\title{
A COMPARISON OF AMERICAN AND HONG KONG CONSUMERS' ATTITUDES TOWARD PRODUCT PLACEMENT IN MOVIES
}

Laurie A. Babin, University of Louisiana Monroe, USA

Claire Stammerjohan, University of Louisiana Monroe, USA

\begin{abstract}
Product placement, which is the appearance of brands in motion pictures, television programs, video games, and other entertainment venues has seen tremendous growth in the United States and worldwide. However, product placement is relatively new in Hong Kong and has seen some backlash among consumers. Several studies have examined consumers' attitudes toward this practice, and some have compared cross-cultural attitudes. The present study examines attitudinal difference across U.S. and Hong Kong consumers regarding attitudes toward product placement in movies. Results indicate several significant differences in attitudes, indicating a need to consider standardization modification strategies when exporting U.S.-based entertainment to Hong Kong.
\end{abstract}

References available upon request. 